\title{
Pemanfaatan Pedestrian Ways di Koridor Komersial di Koridor Jalan Pemuda Kota Magelang
}

\author{
Marcelina Dwi Setyowati \\ Dosen, Program Studi Arsitektur, Fakultas Sains dan Teknologi, Universitas Teknik Yogyakarta \\ marcelina.dwi@staff.uty.ac.id \\ na.marcelina90@gmail.com
}

\begin{abstract}
ABSTRAK
Pedestrian ways merupakan sarana pencapaian yang dapat melindungi pejalan kaki dari bahaya kendaraan bermotor. Namun, karena penataan yang kurang baik, aman, nyaman dan pencapaian yang sulit menyebabkan pedestrian ways menjadi kurang teratur dan tersegmentasi, sehingga menimbulkan konflik dalam pemanfaatan ruangnya.Koridor Jalan Pemuda merupakan koridor komersial yang strategis, menjadi pusat perbelanjaan dan pusat perekonomian di Kota Magelang. Jalan. Pada tahun 2011 dilakukan pengembangan ruang jalan, yaitu jalur kendaraan tidak bermotor dikembangkan menyatu denganpedestrian ways sehingga menjadi lebih lebar. Hal tersebut memunculkan konflik pemanfaatan ruang jalan seperti penyalahgunaan jalur pedestrian menjadi area parkir kendaraan bermotor, dan permasalahan segmentasi jalan yang menimbulkan kesenjangan jumlah pejalan kaki di area tersebut. Penelitian ini menemukan bahwa faktor-faktor pemanfaatan pedestrian ways di koridor komersial yang berpengaruh di Jalan Pemuda adalah faktor kenyamanan, aksesibilitas, fungsi lahan dan aktivitas, keamanan serta identitas kawasan. Tujuan penelitian adalah untuk mencari karakteristik dan faktor yang dapat mempengaruhi pemanfaatan pedestrian ways di koridor komersial yang sesuai agar dapat menyelesaikan permasalahan yang timbul sehingga dapat memaksimalkan pemanfaatan pedestrian ways di area tersebut. Metode penelitian yang digunakan adalah metode deduktif kualitatif. Metode yang digunakan untuk menemukan permasalahan di lapangan kemudian dibuat rangka penelitiannya dan mengolahnya secara kuantitatif untuk menentukan hasil yang kualitatif.
\end{abstract}

Kata kunci : pedestrian ways, koridor jalan, koridor komersial

\begin{abstract}
Pedestrian ways are a means to protect pedestrians from the dangers of motor vehicles. However, due to poor arrangement, safe, comfortable and difficult to access cause pedestrian ways become less regular and segmented, causing conflict in the utilization of space.Pemuda street Corridor is a strategic commercial corridor, becoming a shopping center and economic center in Magelang City. In 2011, the road corridor development was conducted, ie the non-motorized lanes were integrated into the pedestrian ways so that it became wider. This led to conflicts in the utilization of road spaces such as misuse of pedestrian paths into motor vehicle parking areas, and road bagiantation problems that caused a gap in the number of pedestrians in the area. This study found that factors of utilization of pedestrian ways in influential commercial corridors on Jalan Pemuda are convenience, accessibility, land use and activity, safety and regional identity. The purpose of this research is to find the characteristics and factors that can influence the utilization of pedestrian ways in the appropriate commercial corridor in order to solve the problems that arise so as to maximize the utilization of pedestrian ways in the area.The method used in this study is a qualitative deductive method. The method used to find problems in the field then made the framework of research and process it quantitatively to determine the qualitative results.
\end{abstract}

Keywords: pedestrian ways, street, commercial corridor

\section{Pendahuluan}

1.1 Konflik Pemanfaatan Ruang Jalan di Area Komersial

Ruang jalan di area komersial merupakan ruang publik yang disediakan untuk 
mewadahi berbagai macam interaksi sosial, dimana masyarakat dapat dengan mudah mengaksesnya. Koridor jalan komersial merupakan ruang publik yang berbentuk linier yang didominasi kegiatan dengan fungsi komersial. Banyaknya jenis pengguna yang harus diwadahi dalam sebuah ruang jalan dapat menimbulkan adanya konflik pemanfaatan ruang. Konflik dapat diartikan sebagai perbedaan persepsi mengenai kepentinganterjadi ketika tidak terlihat adanya alternatif. Selama masih ada perbedaan tersebut, konflik tidak dapat dihindari dan selalu akan terjadi (Wirawan; 2010: 1-2).

\subsection{Segmentasi Ruang Jalan}

Bagi kebanyakan orang berada di atas jalur pejalan kaki merupakan tempat paling aman dan nyaman untuk berjalan kaki tanpa harus merasa terganggu oleh kendaraan lain yang melintas. Namun, hal tersebut menimbulkan adanya segmentasi antar pengguna ruang jalan, yang berakibat pada semakin terbatasnya pergerakan pejalan kaki di suatu area. Sebagai contoh saat dua jalur pejalan kaki terpisah oleh jalur kendaraan bermotor dengan volume kepadatan tinggi, maka pergerakan pejalan kaki menjadi terbatas untuk mengakses letak jalur pejalan kaki yang berseberangan.

\subsection{Pertimbangan Pemilihan Lokasi}

Koridor Jalan Pemuda merupakan jalan arteri sekunder satu arah dengan panjang \pm 823 meteryang saat ini berubah status menjadi jalan kota yang dikelola oleh pemerintah kota. Koridor tersebut letaknya sangat strategis karena merupakan pusat perbelanjaan dan pusat perekonomian di Kota Magelang. Banyak aktivitas yang terjadi di koridor Jalan Pemuda Kota Magelang, para pelaku aktivitas tersebut antara lain adalah penjual, pejalan kaki, pengendara kendaraan umum, pengendara kendaraan pribadi, dan pengendara kendaraan tidak bermotor. Pada awalnya koridor Jalan Pemuda ini terdiri empat jalur, yaitu jalur pejalan kaki (pedestrian ways)sebelah barat, jalur kendaraan bermotor, jalur kendaraan tidak bermotor, dan jalur pejalan kaki(pedestrian ways) sebelah timur. Jalur pejalan kaki dengan jalan mempunyai perbedaan ketinggian lantai yang berbeda dan pada jalan utama terdapat pembatas antara jalur lambat dan jalur utama. Pada gambar 1 dibawah ini menunjukkan kondisi eksisting jalur pejalan kaki (pedestrian ways) di koridor Jalan Pemuda sebelum tahun 2011.

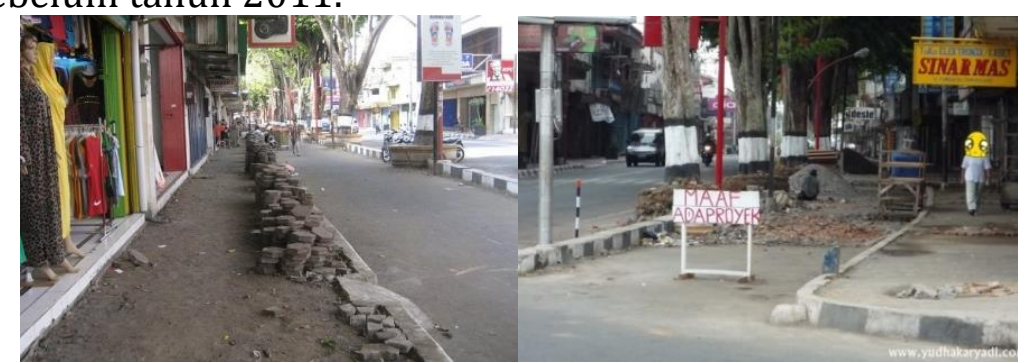

Gambar 1. Jalur Pejalan Kaki diJalan Pemuda Sebelum Tahun 2011

(Sumber: www.pecinan-magelang-topengireng.wordpress.com dan www.pembangunan_magelangwww.yudhakaryadi.com)

Pada tahun 2011 pemerintah Kota Magelang melakukan renovasi ruang jalan sehingga di sepanjang Jalan Pemuda jalur kendaraan tidak bermotor yang dikembangkan menyatu dengan jalur pejalan kaki di sebelah timur. Jalur pejalan kaki dan jalur lambat memiliki level lantai yang sama sedangkan jalan utama dan jalur pejalan kaki terdapat perbedaan level lantai. Pada gambar berikut ini menunjukkan kondisi eksisting koridor Jalan Pemuda setelah tahun 2011. 


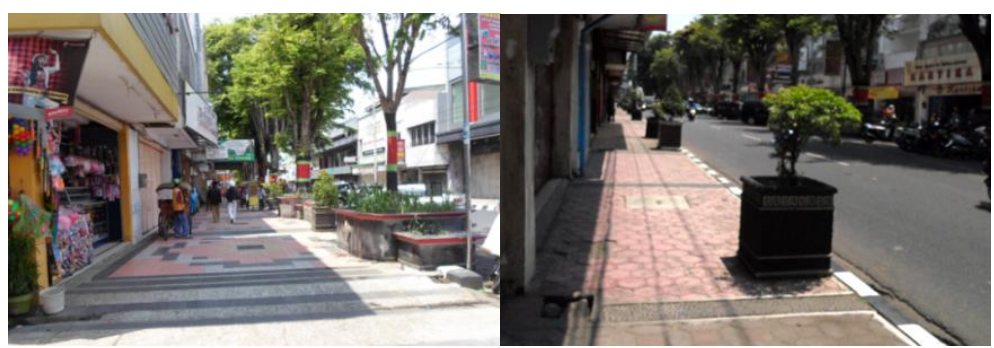

Gambar 2. Jalur Pejalan Kaki diJalan Pemuda Tahun 2015

(Sumber: observasi lapangan, 2015)

Penyatuan antara jalur lambat (jalur kendaraan tidak bermotor) dan pedestrian waysmenyebabkan adanya beberapa permasalahan dalam penggunaan ruang jalan, antara lain terdapat kendaraan roda dua yang melintas menyalahi jalur yang ada (jalan satu arah) dengan menggunakan jalur kendaraan tidak bermotor. Pada gambar berikut ini menunjukkan adanya penggunaan ruang jalan (jalur pejalan kaki) sebagai area parkir.Area tepi jalur kendaraan tidak bermotor digunakan sebagai parkir kendaraan roda dua, meskipun sudah disediakan area khusus untuk area parkir kendaraan di tepi jalur utama.

Para pengguna jalur pejalan kaki mengaku merasa terganggu dengan kendaraan bermotor yang ikut melintasi jalur pejalan kaki, selain itu juga menyebabkan rusaknya material. Material perkerasan jalur pejalan kaki yang digunakan juga dirasa belum layak karena berupa keramik yang akan menjadi licin saat hujan, sehingga menyebabkan ketidaknyamanan pada penggunanya, terutama bagi para difabel karena selain tidak nyaman juga tidak aman. Para pengguna lebih menyukai penggunaan bahan yang tidak licin sebagai perkerasan seperti paving tau batu-batuan.

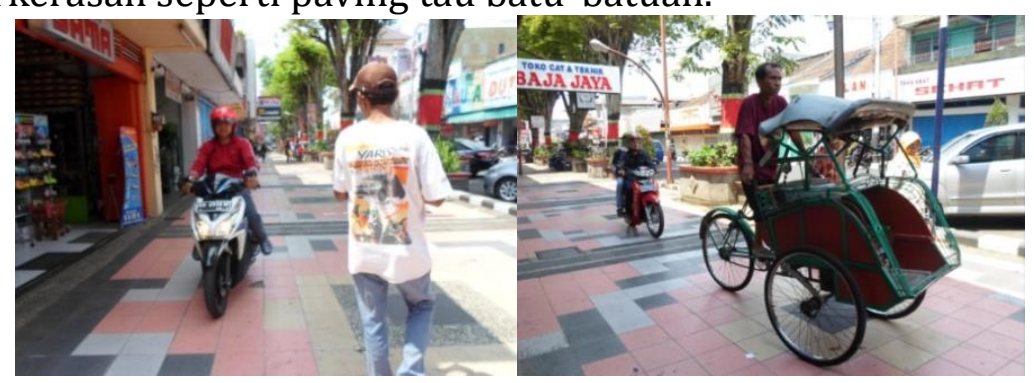

Gambar 3. Kendaraan Bermotor Melewati Pedestrian Ways (Sumber: observasi lapangan, 2015)

Pemerintah Kota Magelang pada tahun 2014 telah menetapkan peraturan untuk Jalan Pemuda agar bebas dari pedagang kaki lima. Oleh karena itu, pedagang kaki lima direlokasi ke Pasar Rejowinangun. Sebelum pedagang kaki lima direlokasi, pedestrian ways di Jalan Pemuda merupakan ruang publik yang cukup aktif karena banyak pengunjung dari berbagai kalangan yang mendatanginya.Meskipun saat ini pedagang kaki lima dilarang berjualan secara menetap, pada kondisi sekarang menunjukkan masih terdapat beberapa pedagang kaki lima yang berjualan di sepanjang koridor Jalan Pemuda. Pada gambar berikut ini menunjukkan adanya pedagang kaki lima di koridor Jalan Pemuda. 


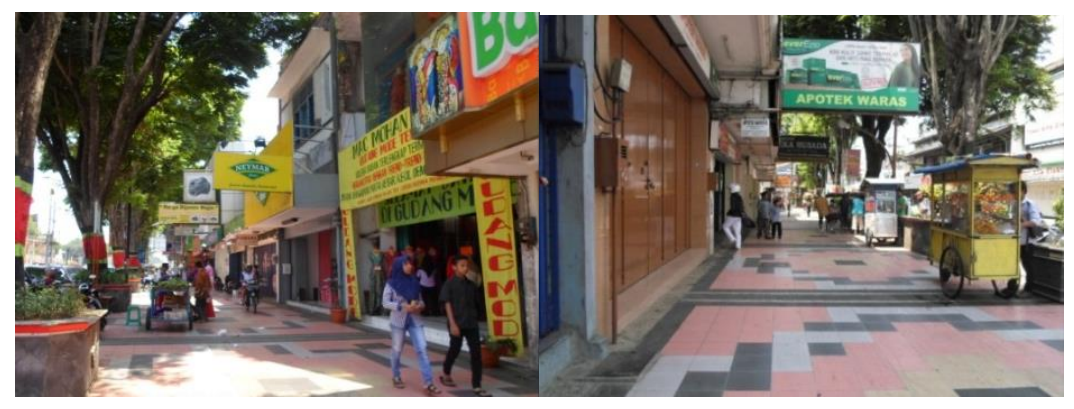

Gambar 4. Jalur Pejalan Kaki(Pedestrian Ways) Dijadikan Area Berjualan Pedagang Kaki Lima

(Sumber: observasi lapangan, 2015)

Berdasarkan hasil pengamatan penulis, kondisi fisik Jalan Pemuda Kota Magelang saat ini yang belum sesuai adalah sebagai berikut:

1. Konektivitas jalur pejalan kaki kurang, karena adanya segmentasi ruang jalan.

2. Ketimpangan jumlah pejalan kaki di trotoar (pedestrian ways) barat dan timur, bagian barat lebih sepi dibandingkan bagian timur.

3. Aksesibilitas untuk penyandang disabilitas kurang (bahkan tidak diwadahi), contoh perbedaan ketinggian lantai jalan yang cukup tinggi, dan tidak ada jalur khusus disabilitas.

4. Pedagang kaki lima yang dapat menjadi daya tarik bagi pengunjung dan obyek yang memperkuat citra koridor komersial menjadi kurang kuat karena keberadaannya dihilangkan.

Berdasarkan permasalahan penelitian yang telah dijelaskan, maka dapat dirumuskan pertanyaan penelitian sebagai berikut:

1) Bagaimana karakteristik pemanfaatan pedestrian waysdikoridor komersial di Jalan Pemuda Magelang?

2) Faktor apa saja yang berpengaruh pada pemanfaatan pedestrian ways di koridor komersial di Jalan Pemuda Magelang?

\section{Bahan dan Metode}

\subsection{Koridor Komersial}

Menurut Bishop (1989), koridor jalan komersial merupakan koridor jalan yang pemanfaatan ruang di sepanjang jalannya untuk kegiatan komersial, perkantoran yang kompleks dan pusat pekerjaan di dalam kota. Karakteristik Koridor Komersial menurut PPS (Project for Public Space) adalah sebagai berikut:

1) Kenyamanan dan identitas

2) Aksesibilitas

3) Fungsi lahan (land use) dan Aktivitas

4) Fungsi Sosial

\subsection{Pedestrian Ways}

Jalur pejalan kaki (pedestrian ways) adalah jalur pejalan kaki, yaitu lintasan yang diperuntukkan untuk berjalan kaki, dapat berupa trotoar (DPU, 1999). Jalur pedestrian dalam konteks perkotaan biasanya dimaksudkan sebagai ruang khusus untuk pejalan kaki yang berfungsi sebagai sarana pencapaian yang dapat melindungi pejalan kaki dari 
bahaya yang datang dari kendaraan bermotor.Menurut Untermann (1984), kriteria jalur pejalan kaki (pedestrian ways) antara lain sebagai berikut:

1) Keamanan (safety), pejalan kaki harus mudah bergerak atau berpindah dan berlindung dari kendaraan bermotor.

2) Aksesibiltas (accesibility), pejalan kaki harus memiliki rute sesingkat mungkin (jarak terpendek) yang bebas hambatan dari suatu lokasi ke lokasi tujuan lain.

3) Kenyamanan (comfort), pejalan kaki harus memiliki jalur yang mudah dilalui, seperti halnya kendaraan bermotor berjalan di jalan bebas hambatan.

4) Daya tarik (attractiveness), pada tempat tertentu diberikan elemen yang dapat menimbulkan daya tarik seperti elemen estetika, lampu penerang jalan, lansekap, dll.

Pedestrian ways (jalur pejalan kaki) seharusnya memenuhi kriteria bisa digunakan oleh kelompok masyarakat, termasuk warga yang sudah lanjut usia, penyadang cacat, perempuan (yang sedang mengandung) dan anak-anak.

Melalui penelitian Persepsi Pengguna terhadap Jalur Pejalan Kaki Jalan Pemuda Kota Magelang (Ikhsani\& Khadiyanta, 2015) ditemukan bahwa pengguna di Jalan Pemuda Kota Magelang didominasi oleh pengguna dengan usia dewasa antara 15-30, karena pengguna usia tersebut masih mampu melakukan kegiatan berjalan kaki dengan baik apabila dibandingkan dengan pengguna yang berusia lanjut maupun anak kecil.

Tabel 1. Persepsi masyarakat terhadap kondisi fisik jalur pejalan kaki menurut pengguna

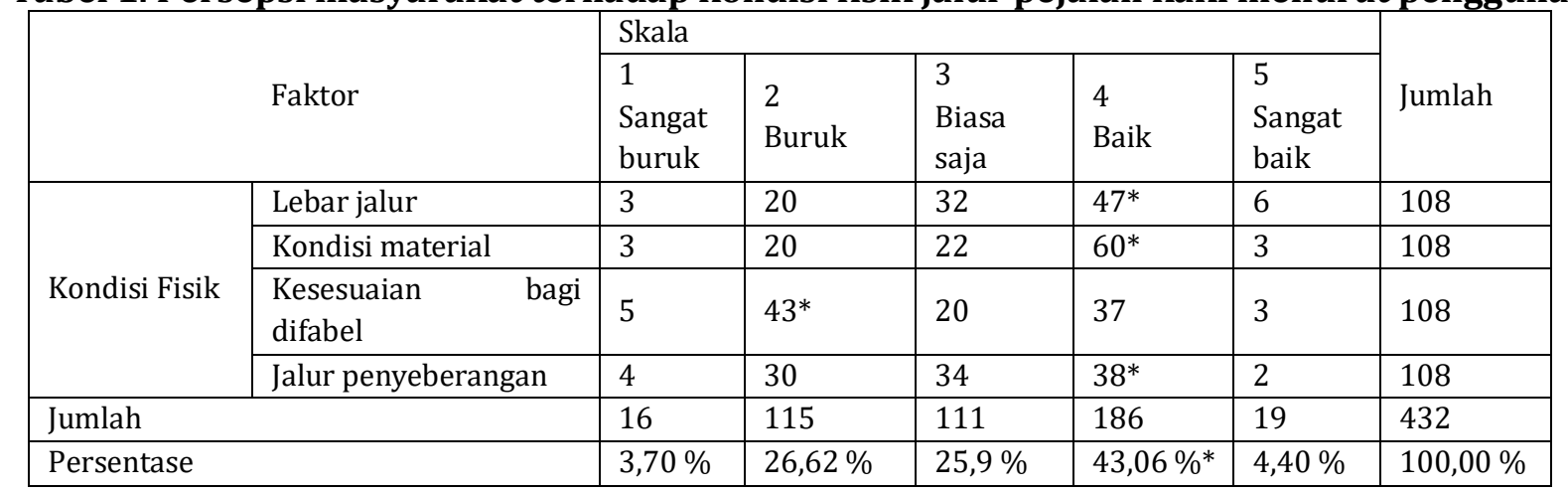

*) Pilihan dominan pengguna

(Sumber: Jurnal Ruang UNDIP, Ikhsani \& Khadiyanta, 2015)

\subsection{Landasan Teori}

Koridor komersial merupakan konsentrasi toko retail, yang melayani area perdagangan umum di sepanjang jalan dengan kondisi aktivitas yang padat, dan dilengkapi dengan jalur pejalan kaki sebagai pendukungnya. Faktor-faktor padakoridor komersial antara lainmencakup kenyamanan dan identitas, aksesibilitas, fungsi lahan (land use) dan aktivitas, dan fungsi sosial.Jalur pejalan kaki (pedestrian ways) adalah ruang khusus berupa lintasan untuk berjalan kaki yang berfungsi sebagai sarana pencapaian bagi pejalan kaki. Faktor-faktor padapedestrian ways antara lain mencakupkeamanan (safety), kemudahan pencapaian/aksesibilitas (accessibility), kenyamanan (comfort), daya tarik (attractiveness). Ringkasan karakteristik pada teori yang terkait dengan penelitian dapat dilihat pada gambar berikut ini: 


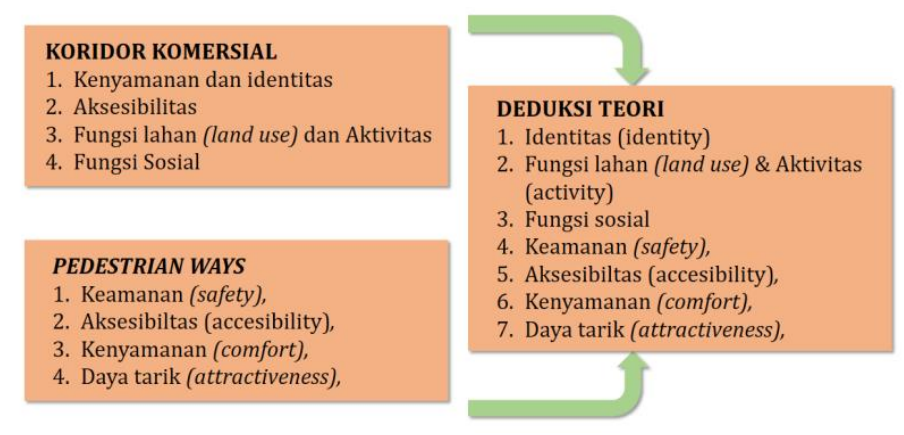

Gambar 5. Deduksi Teori

(Sumber: penulis)

Dari deduksi teori didapatkan faktor identitas (identity), fungsi lahan (land use) dan aktivitas (activity),fungsi sosial, keamanan (safety), aksesibilitas (accesibility), kenyamanan (comfort), dan daya tarik (attractiveness).Faktor-faktor tersebut kemudian digunakan sebagai penjabaran pada faktor-faktor yang berpengaruh pada pemanfaatanpedestrian ways di koridor komersial di Jalan Pemuda Kota Magelang.

\subsection{Metode Penelitian}

Metode yang digunakan dalam penelitian adalah metode deduktif kualitatif yang dikombinasikan dengan metode kuantitatif. Metode yang digunakan untuk menemukan permasalahan di lapangan dibuat rangka penelitiannya dan mengolahnya secara kuantitatif untuk menentukan hasil yang kualitatif. Pengumpulan data meliputi data primer, dan sekunder yang diperoleh melalui hasil pengamatan di lapangan, studi. Datadata tersebut kemudian dianalisa dan digunakan untuk merumuskan karakteristik dan faktor-faktor apa saja yang berpengaruh. Jenis penelitian yang digunakan adalah kualitatif yang dianggap dapat menjelaskan tentang gejala atau fenomena yang terjadi di lapangan secara lengkap dan menyeluruh. Proses penelitian bersifat deduktif, dimana dalam menjawab rumusan masalah dengan menggunakan variabel, indikator dan parameter yang dirumuskan dari landasan teori.

\section{Hasil dan Diskusi}

Lokasi koridor Jalan Pemuda yang memiliki panjang \pm 823 meter ini sangat strategis karena merupakan pusat perbelanjaan dan pusat perekonomian yang berbatasan dengan dua node besar sekaligus landmark di Kota Magelang yaitu Alun-alun Kota Magelang di sisi utara dan Pasar Rejowinangun di sisi selatan sehingga koridor ini menjadi jalur pilihan masyarakat baik kendaraan dan pejalan kaki (didominasi karyawan toko dan anak sekolah). Pada tabel berikut ini menunjukkan matriks opini pengguna pedestrian ways di koridor komersial di Jalan PemudaMagelang.

Tabel 2. Matriks opini pengguna di Jalan Pemuda Kota Magelang

\begin{tabular}{|c|c|c|c|c|}
\hline \multirow{2}{*}{ Faktor } & \multirow[b]{2}{*}{ Elemen } & \multirow[b]{2}{*}{ Karakteristik } & \multicolumn{2}{|c|}{ Keterangan } \\
\hline & & & $\begin{array}{c}\text { Bagian } \\
\text { barat }\end{array}$ & $\begin{array}{c}\text { Bagian } \\
\text { timur }\end{array}$ \\
\hline \multirow{5}{*}{$\begin{array}{l}\text { 1. Fungsi lahan } \\
\text { (land use) dan } \\
\text { aktivitas }\end{array}$} & \multirow{3}{*}{$\begin{array}{l}\text { Fungsi lahan dan aktivitas } \\
\text { lahan (land use) }\end{array}$} & Jenis fungsi lahan & $\bullet$ & $\mathbf{0}$ \\
\hline & & Waktu aktivitas & $\bullet$ & $\bullet$ \\
\hline & & Pelaku & $\bullet$ & $\bullet$ \\
\hline & \multirow[b]{2}{*}{ Persebaran aktivitas komersial } & Ragam sektor usaha formal & $\bullet$ & $\bullet$ \\
\hline & & $\begin{array}{l}\text { Ragam sektor usaha } \\
\text { informal }\end{array}$ & $\mathbf{0}$ & o \\
\hline 2. Fungsi sosial & Persebaran aktivitas sosial & Ragamaktivitas sosial & $\mathbf{0}$ & $\mathbf{0}$ \\
\hline
\end{tabular}




\begin{tabular}{|c|c|c|c|c|}
\hline \multirow{4}{*}{ Faktor } & \multirow{4}{*}{ Elemen } & \multirow[b]{2}{*}{ Karakteristik } & \multicolumn{2}{|c|}{ Keterangan } \\
\hline & & & $\begin{array}{c}\text { Bagian } \\
\text { barat }\end{array}$ & $\begin{array}{l}\text { Bagian } \\
\text { timur }\end{array}$ \\
\hline & & Pelaku Kegiatan & 0 & $\bullet$ \\
\hline & & Waktu Kegiatan & $\boldsymbol{0}$ & $\boldsymbol{0}$ \\
\hline \multirow{8}{*}{$\begin{array}{l}\text { 3. Kenyamanan } \\
\text { (comfort) }\end{array}$} & \multirow{5}{*}{ Sirkulasi } & Jalur difabel & 0 & $\mathrm{O}$ \\
\hline & & Dimensi jalan & $\bullet$ & $\bullet$ \\
\hline & & Dimensi Jalur pedestrian & $\bullet$ & $\bullet$ \\
\hline & & Waktu perjalanan & $\bullet$ & $\bullet$ \\
\hline & & Jarak perjalanan & $\bullet$ & $\bullet$ \\
\hline & Kondisi alam dan Iklim & $\begin{array}{l}\text { Terdapat pelindung dari } \\
\text { panas dan hujan }\end{array}$ & $\mathbf{0}$ & $\mathbf{0}$ \\
\hline & \multirow{2}{*}{ Street furniture } & Jenis street furniture & 0 & $\bullet$ \\
\hline & & Lokasi peletakan & 0 & $\mathbf{0}$ \\
\hline \multirow{8}{*}{$\begin{array}{l}\text { 4. Aksesibilitas } \\
\text { (accessibility) }\end{array}$} & \multirow{3}{*}{ Material perkerasan } & Jenis material & $\bullet$ & $\mathbf{0}$ \\
\hline & & Warna & $\bullet$ & $\bullet$ \\
\hline & & Tekstur & $\bullet$ & $\mathbf{0}$ \\
\hline & Level permukaan & Level permukaan jalan & $\mathbf{0}$ & $\mathbf{0}$ \\
\hline & \multirow{2}{*}{ Barrier } & Jenis barrier & $\mathbf{0}$ & $\bullet$ \\
\hline & & Jarak barrier & $\bullet$ & $\bullet$ \\
\hline & \multirow{2}{*}{ Ramps } & Kemiringan & $\mathbf{0}$ & $\bullet$ \\
\hline & & Lokasi ramp & $\bullet$ & $\bullet$ \\
\hline \multirow{3}{*}{$\begin{array}{l}\text { 5. Livabilitas } \\
\text { (livability) }\end{array}$} & \multirow{2}{*}{$\begin{array}{l}\text { Daya tarik kawasan } \\
\text { (attractiveness) }\end{array}$} & Jenis kegiatan khusus & $\mathbf{0}$ & $\mathbf{0}$ \\
\hline & & Pelaku kegiatan khusus & $\bullet$ & $\bullet$ \\
\hline & Interaksi sosial & Jenis interaksi sosial & $\mathbf{0}$ & $\mathbf{0}$ \\
\hline \multirow{2}{*}{$\begin{array}{l}\text { 6. Konektivitas } \\
\text { (connectivity) }\end{array}$} & Transportasi publik & Jenis transportasi publik & $\bullet$ & $\bullet$ \\
\hline & Titik transit & Titik halte & O & O \\
\hline \multirow{3}{*}{$\begin{array}{l}\text { 7. Identitas } \\
\text { kawasan } \\
\text { (identity) }\end{array}$} & \multirow{2}{*}{ Reklame } & Ukuran reklame & $\bullet$ & $\mathbf{0}$ \\
\hline & & Penempatan reklame & $\bullet$ & 0 \\
\hline & Elemen estetika & Gaya arsitektur & $\boldsymbol{0}$ & $\boldsymbol{0}$ \\
\hline Simbol & Keterangan & & & \\
\hline$\bullet$ & Sesuai & & & \\
\hline ○ & Kurang sesuai & & & \\
\hline 0 & Tidak sesuai & & & \\
\hline
\end{tabular}

Hasil analisa temuan lapangan kemudian dilakukan diskusi dengan landasan teori dan temuan baru yang berkaitan dengan karakteristik pemanfaatan pedestrian ways di koridor komersial, dan elemen apa saja yang berpengaruh pemanfaatan pedestrian ways di koridor komersial di koridor Jalan Pemuda Kota Magelang.

3.1 Karakteristik Pemanfaatan Pedestrian Ways di Koridor Komersial Jalan Pemuda Kota Magelang

Karakteristik pemanfaatan pedestrian ways di koridor komersial Jalan Pemuda yaitu karakter atau sifat-sifat tertentu yang mencirikan bahwa pedestrian ways tersebut sesuai dengan citra koridor Jalan Pemuda sebagai koridor komersial.Karakteristik yang menonjolyang dapat diamati di koridor Jalan Pemuda, antara lain sebagai berikut:

1. Pemilihan material yang kurang nyaman untuk pejalan kaki dan kendaraan tidak bermotor (sepeda dan becak)

2. Perbedaan level permukaan jalan di zona berbeda

3. Fungsi lahan (land use) dan fungsi bangunan mix used. Pedestrian ways digunakan sebagai jalur pejalan kaki, jalur kendaraan tidak bermotor dan kadang digunakan sebagai tempat berjualan pedagang kaki lima. Bangunan tidak hanya berfungsi sebagai pertokoan tetapi juga hunian, pertokoan, dan kantor 
4. Kondisistreet furniture masih baik meskipun kelengkapannya masih sangat kurang.

5. Belum terdapat jalur difabel

6. Daya tarik kawasan kurang

7. Karakter visual ruang jalan kurang

\subsection{Faktor Pemanfaatan Pedestrian Ways di Koridor Komersial}

Faktor pemanfaatan pedestrian ways di koridor komersial dari landasan teori digunakan sebagai dasar untuk mengklasifikasikan karakteristik dari kondisi eksisting yang menonjol di Jalan Pemuda Kota Magelang.
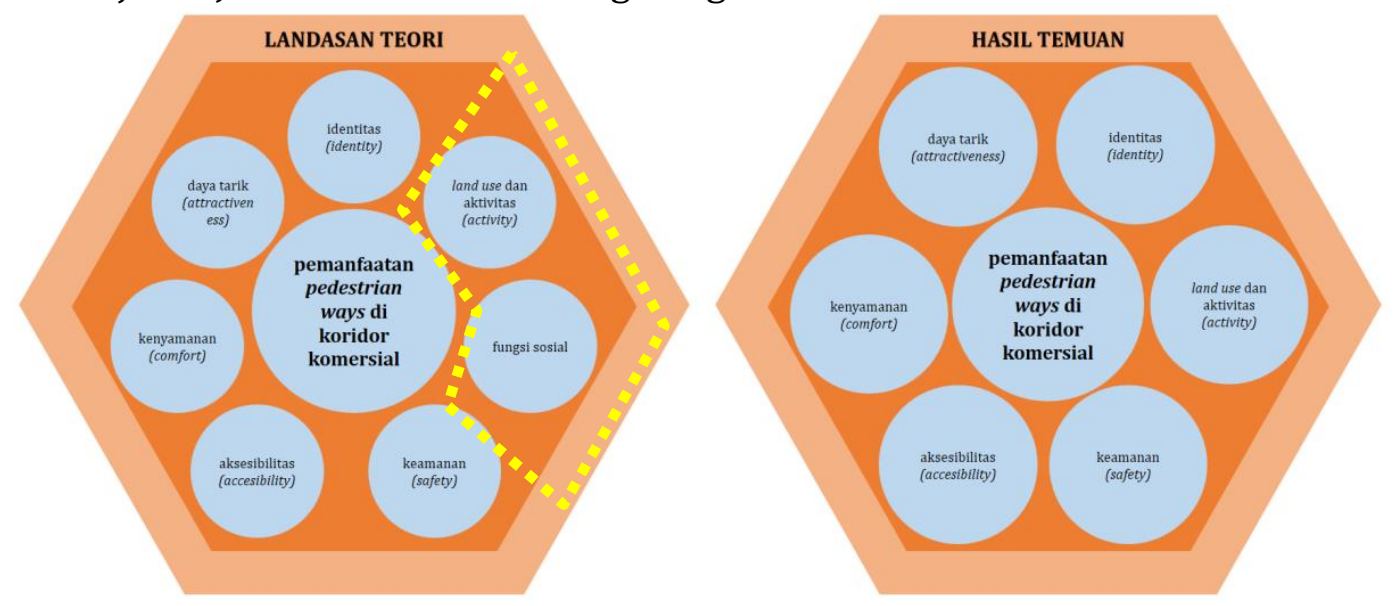

Gambar 6. Faktor Pemanfaatan Pedestrian Ways di Koridor Komersial pada Landasan Teori dan Hasil Temuan (sumber: penulis)

Berdasarkan gambar 6 ditemukan bahwa terdapat beberapa faktor dari landasan teori yang memiliki kesamaan, sehingga dapat dikelompokkan menjadi satu faktor. Faktor tersebut yaitu faktor fungsi lahan dan aktivitas, dan fungsi sosial, yang kemudian dinamakan menjadi faktor fungsi lahan (land use) dan aktivitas. Dasar pertimbangannya dikarenakan faktor fungsi sosial dapat dikategorikan ke dalam bagian dari aktivitas (activity).

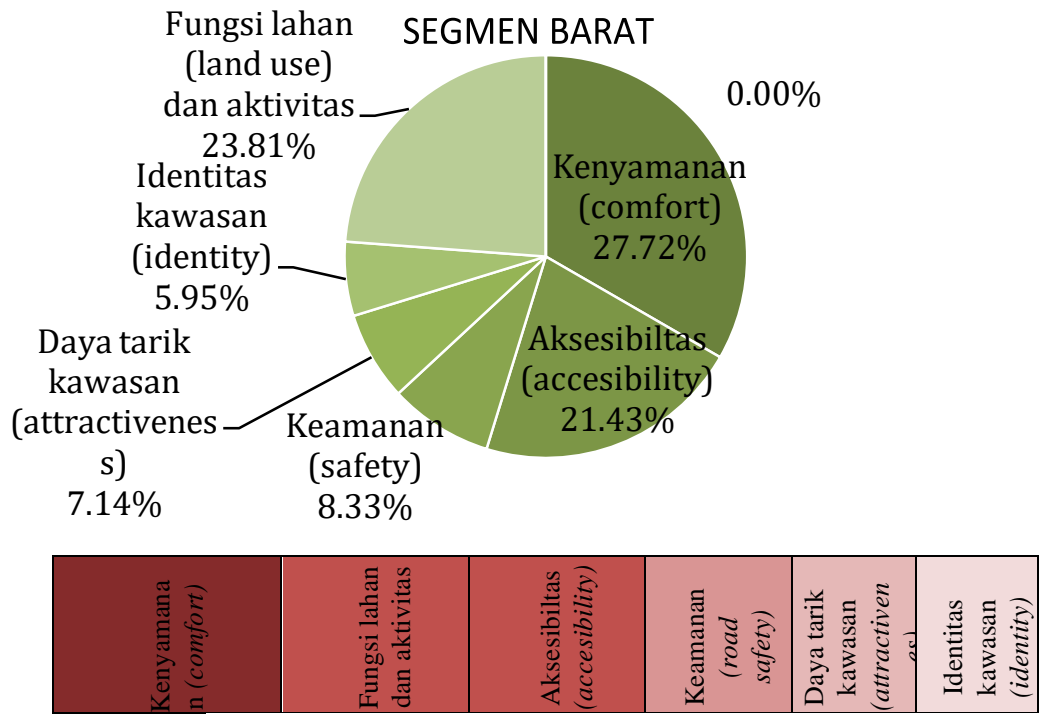

Gambar 7. Persentase Faktor Shared Space Street pada Bagian Barat

(sumber: penulis) 

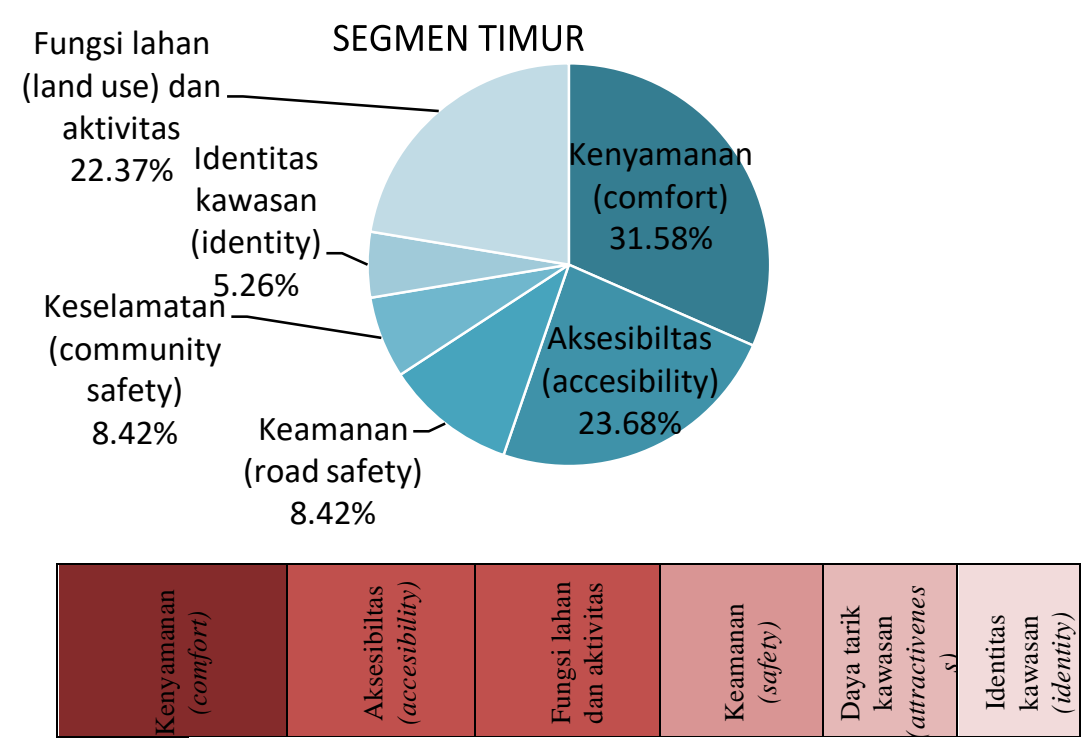

Gambar 8. Persentase Faktor Shared Space Street pada Bagian Timur (sumber: penulis)

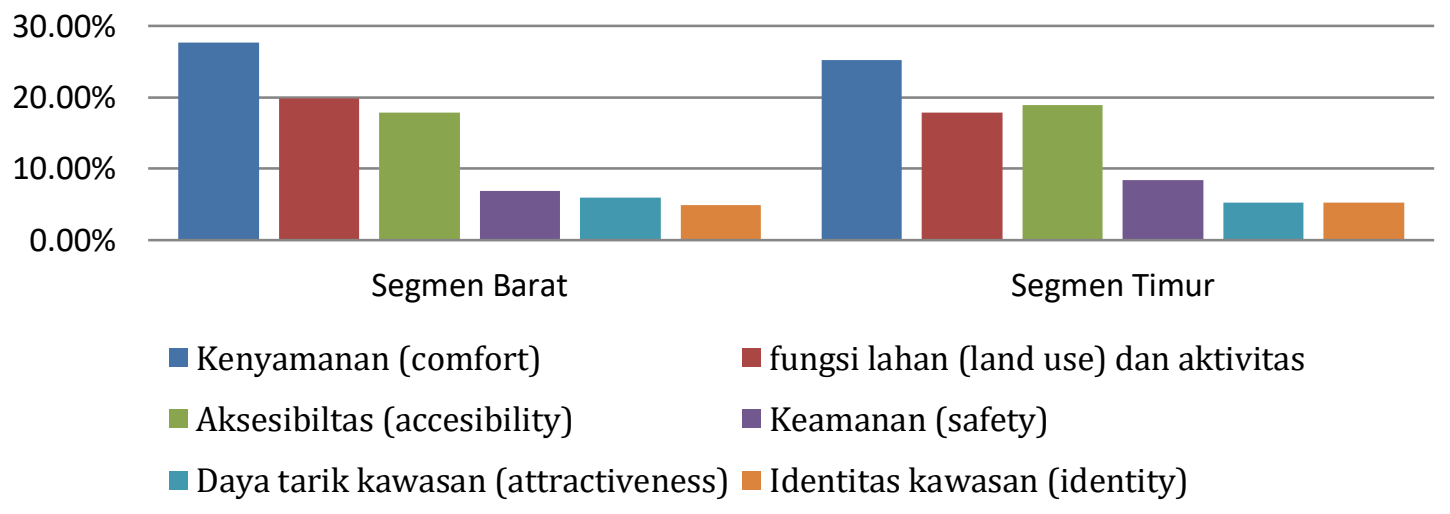

\section{Gambar 9. Perbandingan Persentase Faktor Shared Space Street (sumber: penulis)}

Dari gambar di atas dapat disimpulkan bahwa faktor pemanfaatan pedestrian ways di koridor komersial dengan persentase yang paling tinggi adalah faktor kenyamanan (comfort) pada bagian barat karena memiliki ukuran yang lebih lebar dan street furniture yang lebih lengkap dibandingkan bagian timur. Persentase paling rendah adalah faktor identitas kawasan (identity)pada bagian barat. Padapresentase faktor land use\& aktivitas di bagian barat lebih tinggi dibandingkan bagian timur karena kegiatan komersial di bagian barat lebih beragam daripada bagian timur, yaitu adanya sektor usaha informal (pedagang kaki lima) di bagian barat.

\section{Simpulan}

Karakteristik pemanfaatan pedestrian ways di koridor komersial Jalan Pemuda:

1. Pemilihan material yang kurang nyaman untuk pejalan kaki dan kendaraan tidak bermotor (sepeda dan becak)

2. Perbedaan level permukaan jalan di zona berbeda

3. Fungsi lahan (land use) dan fungsi bangunan mix used. Pedestrian ways digunakan sebagai jalur pejalan kaki, jalur kendaraan tidak bermotor dan kadang digunakan 
sebagai tempat berjualan pedagang kaki lima. Bangunan tidak hanya berfungsi sebagai pertokoan tetapi juga hunian, pertokoan, dan kantor

4. Terdapat street furniture, kondisinya masih baik meskipun kelengkapannya masih sangat kurang

5. Belum terdapat jalur difabel

6. Daya tarik kawasan kurang

7. Karakter visual ruang jalan kurang

Faktor-faktor pemanfaatan pedestrian ways di koridor komersial yang ditemukan di lokasi penelitian berdasarkan urutan tingkat prioritasnya, yaitu sebagai berikut:

1. Kenyamanan (comfort)

2. Aksesibilitas (accesibility)

3. Fungsi lahan (land use) dan aktivitas (activity)

4. Keamanan

5. Daya tarik kawasan (attractiveness)

6. Identitas kawasan (identity)

\section{Daftar Pustaka}

Arifin, Zainal. (2003). Arahan Penataan Ruang Jalan sebagai Ruang Publik pada Kawasan Komersial Kajian pada Setting Elemen Fisik dan Aktifitas.Yogyakarta:Universitas Gadjah Mada, Program Studi Teknik Arsitektur Konsentrasi Desain Kawasan Binaan.

Jusmartinah, R. (2008). Metamorfosis Ruas Jalur Sirkulasi dalam Perencanaan Fasilitas Perkotaan.Surabaya:Thesis, Universitas PGRI Adi Buana, Fakultas Teknik Sipil dan Perencanaan.

Maria, Kiki. (2011). Pola Pemanfaatan Ruang Jalan oleh Pengguna Jalan di Kawasan Komersial, Studi Kasus Kawasan Komersial Blok M, Jakarta Selatan. Yogyakarta: Universitas Gadjah Mada, Program Studi Teknik Arsitektur Konsentrasi Desain Kawasan Binaan.

Ikhsani, LN., Khadiyanta, P. (2015). Persepsi Pengguna terhadap Jalur Pejalan Kaki Jalan Pemuda Kota Magelang. Jurnal Ruang, Vol. 1 Nomor 3, pp.121-130. 